\title{
Un aplique con aspecto de máscara procedente de Medinaceli, Soria
}

\author{
Fernando Morales Hernández, María Jesús Borobio Soto \\ y Ana Carmen Pascual Díez
}

\begin{abstract}
RESUMEN ABSTRACT
En ocasiones, el hallazgo de Occasionally, the finding of certain determinados elementos suntuarios nos informa de las tendencias decorativas del momento y del gusto hacia ciertos objetos. En este trabajo se analiza un aplique de bronce con aspecto de máscara trágica que debió decorar el cabecero de un diván de comedor de los primeros momentos del Imperio Romano.
PALABRAS CLAVE KEYWORDS
Aplique, máscara, bronce romano;
diván, Medinaceli. bronze, couch, Medinaceli.

En el Museo Numantino de Soria, procedente de los fondos del antiguo Museo Celtibérico ( $n^{\circ}$ de registro C.1663, ingresado por compra directa) encontramos, expuesto en vitrina, un curioso aplique de bronce hallado en Medinaceli. Una fotografía de esta pieza se encuentra recogida en la Guía del Museo Numantino '.

Santos Almansa, A.: Mundo Romano. Alto Imperio. En Guía del Museo Numantino, Soria, 1990, pág. $79, n^{\circ} 87$. 


\section{DESCRIPCIÓN}

Es un bronce de fundición, macizo, posiblemente realizado a la cera perdida, con pátina de color verde oscura que ha perdido en gran parte al haber sido sometido a restauración, aunque todavía se aprecian algunos restos en la parte frontal y, especialmente, en el reverso. Dimensiones: 73 $x 73 \mathrm{~mm}$. Su conservación es buena en general, a pesar de algunas grietas a lo largo de la nariz, en el ojo derecho, el peinado y bajo el mentón.

Representa una cabeza femenina de rostro joven, sereno pero hierático, enmarcado por un ancho y elaborado peinado. Ojos grandes y almendrados, con indicación de los párpados y muy ligeramente de los arcos supraciliares; el color blanco del globo ocular se ha conseguido mediante un chapado de plata, donde resaltan las pupilas, huecas, que quizá en su día estuvieron rellenas de algún material; nariz pequeña pero ancha en la base; pómulos suaves, ancho mentón aunque poco marcado, y boca pequeña de labios finos, ligeramente abiertos, con una perforación horizontal que atraviesa la pieza.

El peinado, de labra no muy profunda, se ha concebido con simetría y linealidad en el trazado y minuciosidad en la realización. La masa de pelo que rodea totalmente la cabeza es más gruesa en la parte superior, con un perfil ligeramente apuntado (se aprecia mejor por el reverso), y termina a cada lado en tres tirabuzones que cubren totalmente las orejas. Muestra un tipo de peinado muy común en las máscaras teatrales, formado por largos tirabuzones alineados realizados mediante grupos de dos o tres incisiones ligeramente curvadas que simulan los rizos. Enmarcando todo el pelo, una fina línea de pequeñas incisiones radiales puede interpretarse como una diadema o, más posiblemente, como parte del mismo peinado, ya que éste continúa en el reverso de la pieza.

La parte trasera es plana, y de ella arranca, a $14 \mathrm{~mm}$ del borde superior, un enchufe tubular hueco de $23 \mathrm{~mm}$ de longitud, $45 \mathrm{~mm}$ de diámetro exterior y unos $6 \mathrm{~mm}$ de grosor.

Cayendo desde el borde (aunque en esta zona se aprecia poco por estar algo deteriorada) y extendiéndose por la parte superior del tubo, una serie de incisiones formando amplias ondas parecen indicar el pelo de la parte posterior del peinado; este cuidado detalle de terminación autoriza a pensar que la pieza no sólo tenía una función decorativa frontal, sino que también podía ser vista desde arriba.

No se encuentran en el tubo agujeros para clavos, señal de que el aplique no iba clavado, sino que se encajaría mediante presión, o iría soldado al mueble. 
En resumen, estamos ante un ejemplar singular de muy buena calidad, un aplique decorativo cuyas características representan, sin lugar a dudas, una máscara trágica.

\section{COMENTARIO}

Si nos remontamos a la Comedia Antigua griega, hacia el siglo $\mathrm{V}$ a. de C., las máscaras servían para hacer reir al público, y la mayoría encarnaban personajes ficticios y grotescos, con bocas enormes y rostros contraídos haciendo muecas. Sin embargo, ya había excepciones: un grupo de máscaras que representaban mujeres jóvenes imitaban fielmente el rostro humano?

Esto cambia en la segunda mitad del siglo Iv a. de C. con la Comedia Nueva. Las máscaras se vuelven un medio de expresión donde prevalece el carácter sobre los rostros, el alma sobre la máscara: la cólera, la tristeza, el dolor, la seriedad, etc.

Cuando la máscara teatral fue adoptada definitivamente por Roma hacia comienzos del siglo 1 a. de $\mathrm{C}$., se admite que se introdujo simultáneamente en los dos géneros dramáticos, copiando los modelos de la Comedia Nueva de los griegos. Sin embargo, «un cierto número de máscaras se distinguen de otras, a primera vista, en que la abertura de la boca no tiene nada de anormal, y por consiguiente no altera en absoluto la regularidad de las facciones: estas máscaras pertenecen casi sin excepción a mujeres jóvenes y hombres jóvenes. Y es posible que, en este aspecto, las miniaturas reproduzcan fielmente la realidad" ${ }^{\text {. }}$

En lo que respecta a la forma del peinado se observa un engrosamiento de la masa de pelo sobre la frente y el perfil ligeramente apuntado del mismo, que hay que poner en relación con el "onkos» de las máscaras trágicas, cuya altura podía variar mucho: "On appelait ainsi, dit Pollux, "la partie supérieure du masque qui se dresse en forme de lambda ( $\lambda$ )». $C$ 'est, comme le montrent un trés grand nombre de monuments, un agrandissement conventionnel du front, le plus souvent dissimulé sous la perruque. Le but de l'oncos parait avoir été, d'une part, de retablir les proportions normales du corps, faussées par la matelassure artificielle du torse et

\footnotetext{
2 Navarfe, O.: Persona, en Dictionnaire des Antiquités Grecques et Romaines d'après les textes et les monuments. Rèdigè sous la direction de DAREMBERG, Ch. et SAGLIO, Edm., tome quatriéme, premiére partie, Graz, 1969, pág. 410.

IBIDEM: Pág. 416.
} 
par les hauts cothurnes, et probablement aussi de prêter aux figures tragiques un aspect plus imposants 4.

En cuanto al tipo de peinado, formado por alineación de rizos y tirabuzones, hay que decir que es bastante corriente en las representaciones de máscaras, encontrándose atestiguado ya en Grecia en la Nueva Comedia, en Roma durante la República o en el Imperio ${ }^{5}$, empleándose estas efigies para una gran variedad de fines: estatuillas de terracota, relieves de mármol en teatros, pinturas murales, frentes de sarcófagos, mosaicos, lucernas, etc. Así pues, al no tratarse de un retrato sino de la representación de una máscara, el peinado no tiene valor cronológico ya que, como hemos visto, se trata de un tipo muy común que se hereda y repite a lo largo del tiempo.

Un ejemplar similar al de Medinaceli, de bronce y con función de aplique, se encuentra en el Museo Biscari de Nápoles. Es una «máscara escénica", con rostro de mujer joven, onkos y boca ligeramente abierta que perfora totalmente la pieza. El peinado, muy esquemático, está formado por tirabuzones paralelos rellenos de finas incisiones inclinadas que caen desparramados sobre la frente; tres de ellos a cada lado enmarcando el rostro. Sus dimensiones: altura 10'3 cms; anchura $10^{\prime} 5 \mathrm{cms}^{6}$.

Otro paralelo significativo lo hemos hallado en la Colección Dutuit, en el Musée du Petit Palais de París. Se trata de un aplique de bronce, también de pequeño tamaño (5'8 cms de altura) que figura una «heroína de tragedia" con las características propias de las máscaras trágicas: boca abierta, onkos (en este caso cubierto con un velo), y el típico peinado de tirabuzones paralelos rellenos de incisiones inclinadas, muy parecido al de la pieza anterior. A esto se suma una expresión patética, de ceño fruncido con cejas caídas que se juntan en la base de la nariz, párpados oblicuos donde la pupila hueca queda situada en el borde de los párpados, cerca del rincón interior del ojo. Aunque la datación de estas piezas es a menudo incierta según Petit, el dibujo de los ojos y las distorsiones del rostro destinadas a remarcar el patetismo del personaje le llevan a fecharla como no anterior al siglo $\| \mathrm{d}$. de C. ?.

\section{IBIDEM: Pág. 407.}

5 Bieber, M.: The history of the greek and roman theater. Princeton, 1961. Para la C.N. ver figs. 340 y 330; para la República romana, figs. 568, 570 y 573a; para el Imperio, figs. 785,803 , 805 y 809 .

6 Libertini, G.: II Museo Biscari. Milano-Roma, 1930, págs. 106-107 (n²331), tav. LIV.

7 PETIT, J.: Bronzes antiques de la Collection Dutuit. Grecs, hellénistiques et de l'antiquité tardive. Musée du Petit Palais, Paris, 1980, pág. 133, n.ำ 62. 

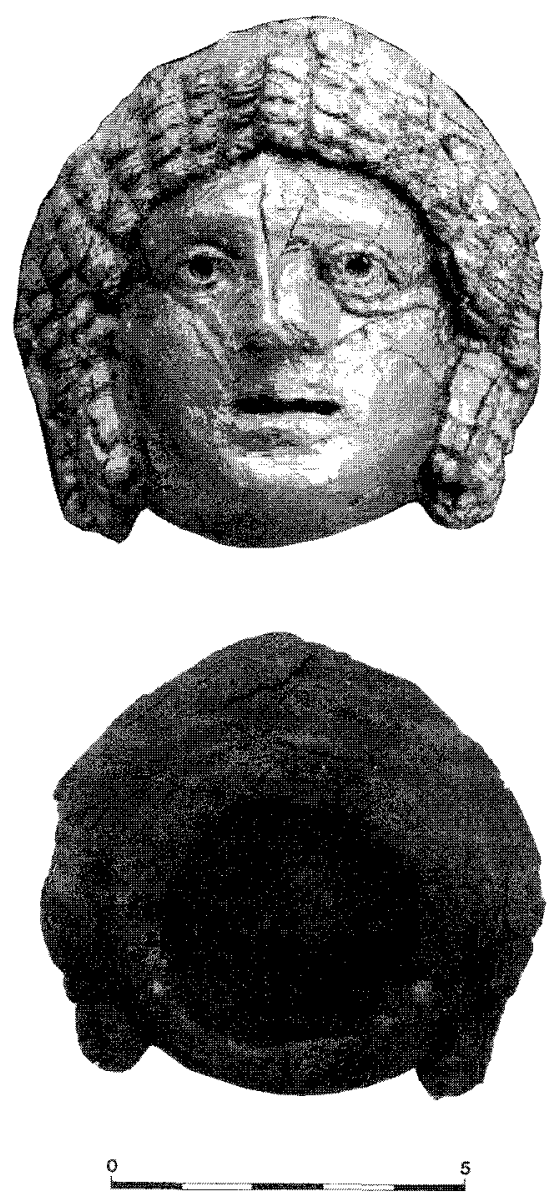

Figura 1. Anverso y reverso del aplique medinense. Foto: A. Plaza. Arch. Museo Numantino.

De igual manera, un aplique de bronce procedente de Lixus, muy parecido a nuestro ejemplar, representa también una máscara teatral. Sus dimensiones: 4' $8 \mathrm{cms}$ de altura por 4'9 $\mathrm{cms}$ de anchura. El ya típico tratamiento del peinado (más acorde que los vistos en las dos piezas anteriores), boca abierta, onkos y expresión serena del rostro coinciden con la máscara medinense ${ }^{8}$.

8 Boube-Piccot, Ch.: Les bronzes antiques du Maroc. Rabat, 1975, nº 82, pl. 34. 
Intentar saber el soporte sobre el que estuvo colocada esta pieza no es, desde luego, tarea fácil. Desde sus orígenes griegos, las máscaras han estado relacionadas con las fiestas y los cultos dionisíacos, heredándolas posteriormente el drama teatral. De igual modo, en Roma eran empleadas en las fiestas otoñales de Tellus y Silvanus y de la vendimia. Es decir, las máscaras siempre han estado rodeadas de un ambiente festivo, de banquete, y relacionadas con los cultos dionisíacos-báquicos, siendo uno de los muchos símbolos de estos cultos.

La variada iconografía dionisíaca utilizada en los adornos habla al espectador antiguo de la esencia del espíritu dionisíaco, y despierta pensamientos de un banquete sereno y de la vida y el triunfo esplendoroso del $\operatorname{dios}^{9}$, sin olvidar que Dionisos, protector del mundo subterráneo, es considerado y honrado desde muy temprano como protector de los muertos, capaz de ofrecer a sus fieles una feliz inmortalidad. $Y$ en este sentido hay que citar una acrótera del Museo de Arlés que representa una máscara trágica con valor apotropáico que adornaba el tejado de un mausoleo o la cubierta de un sarcófago ${ }^{10}$.

Los símbolos dionisíacos alusivos a alegres fiestas y borracheras son temas frecuentemente incorporados en el adorno de camas de banquetes o lechos funerarios indistintamente ${ }^{11}$ como se puede ver en los medallones inferiores y escenas de las guarniciones de los reclinatorios de muchas camas ${ }^{12}$, lo que nos lleva a considerar que este aplique, de innegable iconografía báquica, pudo haber formado parte de una cama o diván de comedor. En consecuencia, habría que relacionarlo con dos apliques de bronce del brazo o reclinatorio de divanes o «camas délicas» halladas en Volubilis, y que son dos figuraciones de Sileno con evidentes paralelos en algunos detalles con la pieza que estudiamos. Así, el sistema de sujección de las piezas marroquies es idéntico al del aplique de Medinaceli; las barbas de Sileno se han representado mediante rizos alineados, y los ojos también están chapados en plata con las pupilas huecas. Boube los considera fabricados en época augústea ${ }^{13}$.

9 Piccot-Boube, C.: Les lits de bronze de Maurétanie tingitane. Bulletin d'Arquéologie Marrocaine, t. IV, 1960, págs. 250-256.

Musée de l'Arles antique. Collections archéologiques d'Arles. Actes Sud, 1996, $n^{2} 48$.

Girard, P.: Lectus, en Dictionnaire des Antiquités Grecques et Romaines d'après les textes et les monuments. Rèdigè sous la direction de Daremberg, Ch.; Sagblio, Edm. et PotTiER, Edm., tome troisiéme, deuxième partie, Graz, 1969, págs. 1.020-1.023.

12 RICHTER, G.M.A.: Ancient furniture. A history of Greeks, Etrucan and Roman furniture. Oxford, 1926, págs 130-135, figs. 311 y 312 . IDEM: The furniture of the Greeks, Etruscans and Romans. Londres, 1966, págs 105-110, figs.532, 548 y 549.

13 Boube-PIсCот, Ch.: Les bronzes antiques..., nº 152 y 154, pl. 66-67 y 69. n 82, pl. 34. 
Para concluir, y recapitulando lo hasta aquí dicho, creemos que se trata de un ejemplar singular con función de aplique decorativo representación de una máscara de teatro que por sus connotaciones dionisíacas/báquicas pudo haber formado parte del cabecero o reclinatorio de un diván de comedor.

Para su datación contamos con escasas referencias, lo que refuerza el comentario de Petit sobre la incierta cronología de estas piezas. No obstante, Bieber afirma que si las máscaras trágicas del Bajo Imperio han sido particularmente atemorizantes, las máscaras más tempranas son con frecuencia bastante más serenas, pudiendo algunas presentar expresiones patéticas, pero todavía sin distorsiones en el rostro ${ }^{14}$, lo que coincide con el comentario de Navarre expuesto al comienzo del trabajo. Según esto y haciendo una valoración global de los paralelos aportados, nos inclinamos a pensar que se trata de una pieza realizada en la primera mitad, o quizá mediados, del siglo । d. de C., lo que viene a coincidir con los datos aportados por otros materiales del yacimiento: cerámicas, sellos de alfarero, monedas, fíbulas, etc, que nos informan de la fuerza con que surge la nueva ciudad, de su momento de mayor auge y desarrollo así como de la capacidad económica de sus habitantes, motivado fundamentalmente por su extraordinaria situación al borde de la importante vía 24 del Itinerario.

La calidad y el detallismo del que hace gala, especialmente en ojos y peinado, apuntan a una fabricación ajena a la zona, quizá incluso pudiera tratarse de una importación itálica, aunque como dice Boube refiriéndose a Marruecos, pero que es igualmente válido para Hispania, "que sean producción de talleres itálicos o de talleres locales son... signo evidente del gusto por el lujo de una clientela enriquecida ávida de imitar, en estos lejanos confines del mundo greco-romano, el estilo de vida de las clases ricas de Roma y de Italia" ${ }^{15}$.

14 BieBER, M.: The history of..., págs. 242-243.

15 Boube-Piccot, Ch.: Les bronzes antiques..., pàg. 25. 